\title{
An analysis of potential adopter attitudes regarding electric vehicles: the case of university students in the United Arab Emirates
}

\author{
Robert M. Bridi*, Naeema Al Hosani \\ United Arab Emirates University, Geography and Urban Sustainability Department, United Arab Emirates \\ * Corresponding Author: rmbridi@uaeu.ac.ae
}

\begin{abstract}
The authors investigate the perceptions, preferences, and valuation of university students in the United Arab Emirates (UAE) regarding the potential to adopt electric vehicles (EVs) for personal transport by surveying a diverse sample of 664 students from the seven emirates (the capital Abu Dhabi, Ajman, Dubai, Fujairah, Ras Al Khaimah, Sharjah and Umm Al Quwain). Details were elicited about social, economic, and environmental factors that influence the potential to adopt EVs for personal transport, perceived advantages of EVs over gasoline automobiles, and knowledge about EVs. The authors employed the SPSS software platform to categorize various factors according to age and gender. Respondents reported a wide variety of perspectives about EVs including environmental benefits and functional drawbacks. Findings show that participant perceptions, preferences, and valuation about EVs are influenced by a multiplicity of social, economic, and environmental factors. Neglect of these factors will undermine the potential to shift preferences toward greater adoption of emerging sustainable transport technologies.
\end{abstract}

\section{KEYWORDS}

electric vehicles; attitudes; perceptions; sustainable transport; United Arab Emirates

Received: 19 September 2019

Accepted: 9 February 2020

Published online: 9 April 2020

Bridi, R. M., Al Hosani, N. (2020): An analysis of potential adopter attitudes regarding electric vehicles: the case of university students in the United Arab Emirates. AUC Geographica 55(1), 38-48

https://doi.org/10.14712/23361980.2020.4

(C) 2020 The Authors. This is an open-access article distributed under the terms of the Creative Commons Attribution License (http://creativecommons.org/licenses/by/4.0). 


\section{Introduction}

According to the International Energy Agency (2018), global $\mathrm{CO}_{2}$ emissions from fuel combustion more than doubled between 1971 and 2016. Such trends have garnered global attention and prompted then Secretary-General of the United Nations, Ban Ki-moon, to declare 2014-2024 the decade of Sustainable Energy for All. One of the objectives of this effort is doubling the global share of renewable energy by 2030 (United Nations 2011). As the steward of this objective, the International Renewable Energy Agency (IRENA), which is headquartered in the United Arab Emirates (UAE), envisioned Renewable Energy Maps as an effort to catalyze renewable energy adoption globally. This effort assesses the costs and impacts of globally doubling renewable energy consumption by investigating the role that the largest energy consuming countries could play in achieving this goal. IRENA's (2018) most recent analysis shows, renewable energy and energy efficiency can, in combination, provide over $90 \%$ of the necessary energy-related $\mathrm{CO}_{2}$ emission reductions. As low-carbon electricity becomes the main energy carrier, the share of electricity consumed in the end-use sectors (buildings, heat, and transport) would need to double, from approximately $20 \%$ in 2015 to $40 \%$ in 2050 . More specifically, in the transport industry, the number of electric vehicles (EVs) on the road would have to increase from approximately 3 million in 2017 to 1 billion in 2050 . To achieve this, most of the passenger vehicles sold from 2040 to 2050 would have to be electric and approximately $75 \%$ of passenger car activity would have to be provided by EVs.

The UAE is the sixth largest producer of oil globally (approximately 2.8 million barrels per day) and the world's third largest net exporter. Initial efforts to diversify the UAE economy capitalized on energy availability and focused on energy intensive industries (aluminum, steel, cement, and construction). This has led to the UAE's per capita primary energy use to be 7 th in the world at 346 gigajoule (GJ) per person per year compared to, for example, the United States which ranks 11th at $300 \mathrm{GJ}$ and Saudi Arabia which ranks 15th at $258 \mathrm{GJ}$ (Sgouridis et al. 2016). The majority (99\%) of domestic transportation in the UAE is road-based using gasoline automobiles and diesel trucks and buses. Road transportation accounts for a large share of gasoline and diesel consumption. With gasoline fuel subsidies, average fuel efficiencies are low and public transportation alternatives are not developed sufficiently. Urban and transportation planning to date have created an automobile-centric transportation system and a car-oriented infrastructure along with a 'car culture' that promotes powerful cars and sport utility vehicles. In 2016, there were approximately 3.4 million or 278 vehicles $/ 1000$ people registered in the UAE (World Health Organization 2018). The transport sector accounts for $22 \%$ of the UAE's domestic energy consumption and is a major contributor of $\mathrm{CO}_{2}$ emissions. Given the expected growth in the UAE's economy and population, the transport sector's $\mathrm{CO}_{2}$ emissions will increase. For example, the number of vehicles in Abu Dhabi alone is projected to increase from approximately 600,000 in 2010 to between 1.5 and 2 million in 2030 . This translates to an increase in vehicle ownership from 264 vehicles/1000 people in 2010 to 642 vehicles/1000 people in 2030 (Sgouridis et al. 2016). To reduce the UAE's $\mathrm{CO}_{2}$ emissions and meet its pre-allotted quota of the Kyoto protocol and COP21 targets, alternative sustainable solutions are required.

A sustainable transport system is a clearly articulated objective of the Department of Transport in the UAE (DOTAD 2009), which demonstrates the potential for replacing $\mathrm{CO}_{2}$ emitting gasoline vehicles with zero emission EVs. Electricity in the UAE is generated almost exclusively by natural gas combined cycle power plants, which implies a low carbon footprint that has the potential to be further reduced with the deployment of solar energy and the planned nuclear power plant expansion (Sgouridis et al. 2016; WBGU 2012). UAE is characterized by a hot arid climate with harsh summer temperatures and mild to warm winters. EVs have demonstrated their ability to operate in the UAE's climate through a sustainable-oriented development effort at Masdar City (Mueller and Sgouridis 2011). Sustainable domestic economic development requires a reliable domestic transport sector that decouples from fossil fuels to meet the need for a long-term sustainable energy supply.

\section{Research Questions, Objectives, and Hypotheses}

The main research question of this study is to what extent do the perceptions, preferences, and valuation of university students in the UAE influence the potential to adopt EVs for personal transport? The sub-questions are to what extent does age group and gender affect university students' decisions? What are the barriers that influence the potential to adopt EVs? What issues related to sustainable transport influence the potential to adopt EVs?

The primary objective of this study is to investigate the perceptions, preferences, and valuation of university students in the UAE regarding the potential to adopt EVs for personal transport. The sub-objectives are to analyze university students' decisions across age and gender; to identify potential barriers to adopting EVs; and to determine if issues related to sustainable transport influence the potential to adopt EVs.

Two hypotheses follow: first, it is the contention of the researchers that perceptions, preferences, and valuation have a determining effect on the potential to adopt emerging pro-environmental technologies, 
such as EVs, for personal transport. Moreover, consumer decisions regarding pro-environmental technologies, such as EVs, are not only based on ethical, technical, or economic factors, but also a host of social factors (e.g., public perception about one product over another, perceived advantage of one product over another, and so on). Second, the success of adopting EVs for personal transport depends on the effectiveness of addressing the issues that potential adopters (e.g., university students) have about them. Sustainable transport strategies have often been directed towards already existing consumers, however, the authors contend that a focus on sustainable transport strategies directed at potential adopters will yield greater results in terms of achieving a more sustainable transport sector.

\section{Previous Studies and Contribution of the Current Research}

Research examining the attitudes of consumers regarding the adoption of EVs may be divided into three intersecting categories: studies that examine consumer perception, driver experience, and societal symbolic meaning. An important caveat to note is the tendency for such studies to quickly become dated and to be country- and region-specific, given local demographic groups, transport policies, and the availability of incentives (Lane 2011). Recent reviews of the research on attitudes of consumers regarding the adoption of EVs provide a comprehensive overview of the academic literature (see, for example, Adnan et al. 2017; Hardman 2019; Liao et al. 2017, 2019; Neves et al. 2019; Qian et al. 2019; Rezvani et al. 2015). These studies examine a variety of related topics including: the methodological approaches that researchers employ, the heterogeneity of the attributes that consumers prefer, and the implications this has for policy-makers and researchers. Among the significant findings is the continued importance that consumers place on economic, technological, environmental, and policy attributes. Issues such as cost, driving range and duration, performance, brand availability, and tax reduction incentives remain on the top of consumer concerns. Moreover, increasing carbon dioxide emissions and associated environmental outcomes, consumer awareness about issues related to sustainability, and informative promotion and understanding of novel technologies such as EVs are key factors that affect the decision-making processes of consumers. In addition, socio-psychological factors have been highlighted by some researchers. These studies reveal the complexities of adopting novel technologies that go beyond utilitarian issues. Some of the topics that are explored include: semiotics and identity, processes through which novel technologies are diffused and adopted, and emotions such as the pleasure associated with driving.
Some authors argue that perceptions have an impact on consumers' potential to purchase EVs. Zhang et al. (2018: 72) claim, “Consumers' perception of incentive policies is intertwined with the perceptions of environmental benefits and risks inherent in the immature technology associated with EVs". This demonstrates that economic incentives alone are not sufficient for making consumers consider adopting EVs. Axsen et al. (2017: 172) point to the ways confusion and misperceptions influence adoption. The authors found "that there is widespread ignorance or misunderstanding" regarding EVs and "Providing information to consumers may be an important step in efforts to support the adoption" of EVs. The authors highlight the importance of information dissemination and adoption in adopting novel technologies. In addition, perceptions about the 'strangeness' and 'trustworthiness' of the technology were identified by potential adopters as barriers pointing to the importance of 'normalizing' emergent technologies. Researchers have also identified misconceptions about other attributes such as driving range, safety, reliability, and recharge time as influencing adoption (e.g., Carley et al. 2019; Coffman et al. 2017; Graham-Rowe et al. 2012; Krause et al. 2016; Schneidereit et al. 2015; Sgouridis et al. 2018; She et al. 2017).

Authors have also examined the impact of real world driver experience on the adoption of EVs. Some authors claim, "individual preferences change significantly after a real experience with an electric vehicle" and concerns regarding commonly held misconceptions such as "driving range, top speed, fuel cost, battery life and charging in city centres and train stations" (Jensen et al. 2013: 24) are subsided. Similarly, in another study, 79 participants drove EVs in the Berlin, Germany metropolitan area for a 6-month field trial. Although participants reported advantages as well as barriers, the authors claim, "Experience can significantly change the perception of EVs" (Bühler et al. 2014: 177). In both studies, however, the positive effects on the general perception of EVs did not necessarily translate into purchase intentions. Other authors found, in general, driver experience was positive with some drawbacks. Drivers reported advantages of recharging over fueling including the convenience of doing so at home or at a public charging station and the financial savings of recharging compared to fueling. Drawbacks included the lack of infrastructure for recharging, the recharging time, and the limited driving range (Figenbaum and Kolbenstvedt 2016; Franke et al. 2017; Graham-Rowe et al. 2012).

While driver experience proved to be an effective method for changing perceptions about EVs, some authors have pointed to the impact that symbolic meanings have on the adoption of EVs. Semiotics are important in two ways: first, cars do not simply provide mobility, but symbolize certain ideas. Second, the ideas that cars symbolize relate to a consumer's identity. Accordingly, cars are not simply about moving 
from one point to another, but about beliefs, values, social status, and so on (Heffner et al. 2006). Skippon et al. (2016) tested the effect of direct experience in a randomised controlled trial with 393 drivers. The drivers in the experimental group drove an EV and the drivers in the control group drove an equivalent gasoline vehicle. Despite the fact that drivers rated the performance of the EVs more highly than the gasoline vehicles, willingness to adopt an EV declined after the experience. The authors claim that consumers prefer products whose symbolic meanings are congruent with personal identity. Symbolic meanings can override the 'rational' calculations evidenced from the experience of driving an EV. In a similar vein, Schuitema et al. (2013: 39), found "that instrumental attributes are important largely because they are associated with other attributes derived from owning and using EVs, including pleasure of driving (hedonic attributes) and identity derived from owning and using EVs (symbolic attributes)". Here the authors show that in situations where a consumer has a 'pro-environment' self-image, he or she is more likely to adopt an EV. Studies such as these as well as others raise the importance of psychological factors relevant for determining behavioural intention (e.g., Axsen et al. 2018; Haustein and Jensen 2018; Noppers et al. 2015; White and Sintov 2017)

Given the limited number of studies in the UAE on the attitudes of consumers regrading EVs, the current research contributes to the advancement of knowledge on sustainable transport by gaining an understanding of the factors that influence university students' perceptions, preferences, and valuation regarding the adoption of EVs in the UAE. The authors employ an on-line survey to determine the social, economic, and environmental factors that influence the perceptions, preferences, and valuation of consumers. In addition, the chi-square test is used to investigate the differences in perceptions, preferences, and valuation among the sample population. A framework is developed and applied that accounts for the social, economic, and environmental factors by categorizing various indicators that influence potential adopters.

\section{Research Design and Methodology}

An online survey was formulated using a predetermined set of questions. The questions addressed issues related to the social (e.g., age, gender), economic (e.g., cost of operating an EV, governmental incentives), and environmental (e.g., sustainable transport, concern for the environment) factors that influence the perceptions, preferences, and valuation of consumers. Perception refers to the way individuals identify, organize, and interpret information to understand their environment. This includes physiological processes involving signals from the human senses to the central nervous system. These are in turn sifted through an individual's memory, learning, and expectations. While such processes are complex, enabling individuals to see and make sense of the world around them, they are unconscious, incomplete, and varying. In this sense perceptions are selective and may be influenced by experience, motives, and emotions (Goldstein 2009). The term preference refers to the decision-making process in the selection of one product over another. Here individuals make a choice to accept or reject one product over another based on their subjective judgement. Preference is not stable over time. Individuals make choices based on a host of factors such as their socio-economic positon, cultural background, religious beliefs, education, and so forth. In this sense preference is malleable and depends on the individual's particular circumstances during a particular time. The ultimate goal, however, is the 'best choice' (real or imagined) based on the degree of contentment or utility that the product provides (Slovic 1995). Valuation denotes the degree of importance that an individual places on an object with the intent of determining a particular course of action. For example, an individual may place a high valuation on an EV because it fulfills the ultimate goal of reducing the individual's carbon footprint. In this sense, valuation affects the behavior of a person and is the basis for that person's action. Moreover, valuation is a reflection of the individual's sense of 'right' and 'wrong'. Simply stated, an individual may place a high valuation on an EV because driving an environmentally friendly vehicle is the 'right' thing to do. One's valuation tends to affect one's attitude and behavior (Bhattacharya and Constantinides 2005).

The survey was used to collect data from a sample population at the United Arab Emirates University (UAEU) in Al Ain, Abu Dhabi, which currently enrolls approximately 14,000 Emirati and international students. A convenience sampling method was used. Convenience sampling is a non-probability sampling method that relies on data collection from population members who are conveniently available to participate in a study. This method was chosen for three reasons: first, it allowed the researchers convenient access to a diverse group of students; second, it is useful for documenting a quality of a phenomenon that occurs in a given sample; third, it is useful for detecting relationships among different phenomena. The use of convenience sampling, however, has been criticized due to the inability to generalise research findings, the relevance of bias, and high sampling error; however, for this study the sample may be representative since it is drawn from a population at the UAEU that is comprised of a diverse group of students from the seven emirates.

Students at the UAEU were sent a link to the online survey. Respondents were mainly engineering, business, and science undergraduate students. The intention was to capture the perceptions, preferences, and 
valuation of individuals who are prospective owners of EVs. In terms of knowledge considerations, the authors consider most of the sample population to be 'technologically savvy'. Technologically savvy individuals have a high level of quantitative skills, and are more equipped to sort out the technical, economic, and environmental differences between EVs and gasoline vehicles. The authors consider these individuals to be likely early adopters only if they perceive EVs to have advantages over gasoline vehicles.

Over 650 responses were received, but some were rejected due to incompleteness. The main objective of the survey was to characterize potential adopters of EVs by elucidating knowledge, preferences, perceptions, attitudes, valuation, and barriers pertaining to the adoption of EVs as part of a plan for sustainable transport. A secondary purpose of the survey was to relate certain socio-economic characteristics including age, gender, and economic incentives to individual perceptions, preferences, and valuation towards EVs. The survey included three sections. The first section of the survey asked for respondents' gender, age, and field of study. Respondents' perceptions, preferences, and valuation towards EV attributes were examined in the second section. In the third section, respondents were questioned about environmental and sustainability issues.

Data was entered in the SPSS software to categorize and establish relationships among a variety of indicators regarding the potential to adopt EVs. A chisquare test was used to investigate the differences in perceptions, preferences, and valuation among the sample population. A chi-square test for independence compares two variables in a contingency table to see if they are related. This is done primarily by testing the null hypothesis of no association between a set of groups and outcomes for a response. The researchers used the standard $5 \%$ or 0.05 cut-off for defining what is a statistically significant difference. Therefore, an associated $p$-value $<0.05$, means that there is significant evidence of an association between variables.

\section{Results and Discussion}

The data from the survey and the analysis of the results are organized in the following way: first, the composition of the respondents including age, gender, and field of study; second, factors such as concern for the environment, trendiness, and drivability that influence the potential to adopt EVs according to age and gender. In addition, the effectiveness of incentives such as government subsidies, transportation requirements, knowledge about EVs, and public opinion that influence the potential to adopt EVs according to age and gender; and third, factors such as price, driving range, and recharge time that discourage the potential to adopt EVs according to age and gender.

\subsection{Composition of the respondents}

The sample indicated that $67 \%$ of the respondents were female and $33 \%$ were male. The discrepancy between female and male respondents reflects the student population at the UAEU where females account for $82 \%$ and males $18 \%$. In addition, most of the respondents were 19 years and below (55\%) and $20-24$ years (36\%) with the remaining $9 \%$ in the $25-29$ years and 30 years or over categories. The age of the respondents reflects the mostly undergraduate student population at the UAEU. In terms of the field of study, Figure 1 shows that the largest group of respondents were from Engineering (25\%), followed by Humanities (20\%), Business (14\%), and Science (14\%). This indicates that many of the respondents are 'technologically savvy'; they have a high level of quantitative skills, and are equipped to sort out the technical, economic, and environmental differences between EVs and gasoline vehicles.

\subsection{Factors that influence the potential to adopt EVs}

There were many factors that respondents identified as influencing their potential to adopt EVs. The results in Table 1 indicate that $64 \%$ identified "good for the environment", followed by "new trend" (28\%), and "test drive" (28\%) influencing their potential to adopt EVs. When the data is disaggregated according to age, $59 \%$ of the respondents in the 19 years and below age group identified "good for the environment" influencing their potential to adopt EVs compared to $34 \%$ in the 20-24 age group, and the remainder in the other age categories; $63 \%$ of the respondents in the 19 years and below age group identified "new trend" influencing their potential to adopt EVs compared to $33 \%$ in

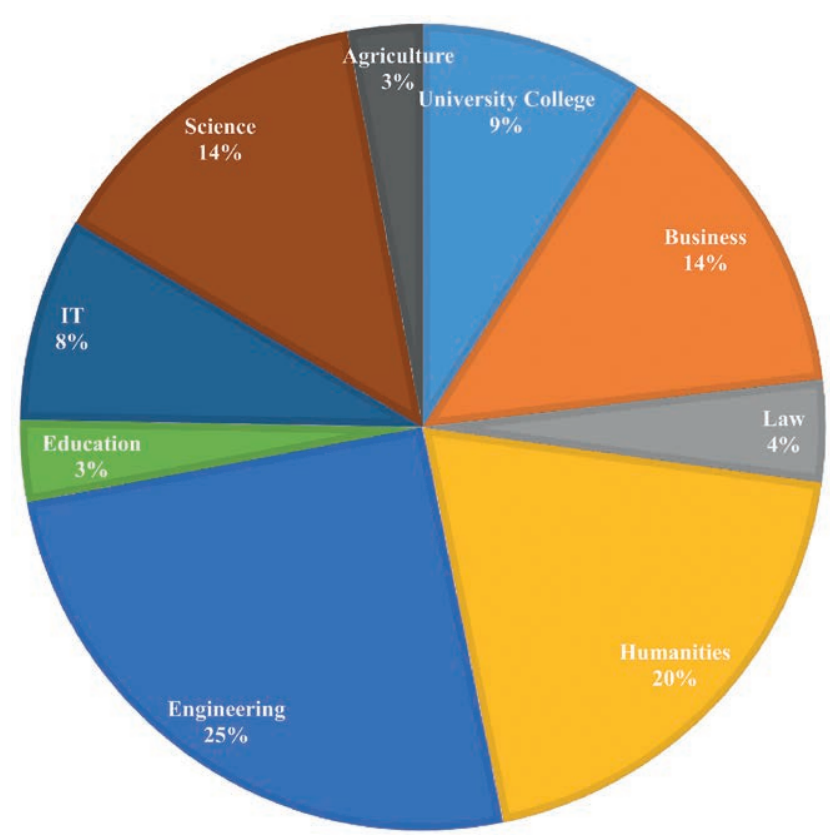

Fig. 1 Number of students from different colleges at the UAEU. 
the $20-24$ age group; and $63 \%$ of the respondents in the 19 years and below identified "test drive" influencing their potential to adopt EVs compared to 33\% in the 20-24 age group. Chi-square tests show statistically significant association between the 19 years and below age group and "good for the environment" (chisquare $=355.04 ; D F=3 ; p \leq 0.00001$ ), "new trend" (chi-square $=185.09 ; D F=3 ; p \leq 0.00001$ ), and "test drive" (chi-square $=148.52 ; D F=3 ; p \leq 0.00001$ ). This shows that the 19 years and below age group is more likely to be influenced by "good for the environment", "new trend", and "test drive" factors than the 20-24 age group.

In addition, although "other people's opinions" (20\%), "cheaper to operate" (24\%), and "low noise level" (22\%) did not rank as high in importance in terms of influencing the potential to adopt EVs, such factors cannot be neglected. When the data is disaggregated according to age, $60 \%$ of the respondents in the 19 years and below age group identified "other people's opinions" influencing their decision to buy an EV compared to $33 \%$ in the $20-24$ age group; $52 \%$ of the respondents in the 19 years and below age group identified "cheaper to operate" influencing their decision to buy an EV compared to $39 \%$ in the $20-24$ age group; and $62 \%$ of the respondents in the 19 years and below identified "low noise level" influencing their decision to buy an EV compared to $32 \%$ in the $20-24$ age group. Chi-square tests show statistically significant associations between the 19 and below age group and "other people's opinions" (chi-square =118.24; $D F=3 ; p \leq 0.00001$ ), "cheaper to operate" (chi-square $=107.94 ; D F=3 ; p \leq 0.00001$ ), and "low noise level" (chi-square $=136.61 ; D F=3$; $p \leq 0.00001$ ). This demonstrates that the 19 years and below age group's potential to adopt EVs is more likely to be influenced by "other people's opinions", "cheaper to operate", and "low noise" factors than the 20-24 age group.

Tab. 1 Factors that influence the decision to buy an electric vehicle

\begin{tabular}{|l|c|c|}
\hline $\begin{array}{l}\text { Factors that influence the } \\
\text { decision to buy an electric } \\
\text { vehicle }\end{array}$ & Frequency & Percentage \\
\hline Good for the environment & 424 & 63.7 \\
\hline Other people's opinions & 135 & 20.3 \\
\hline Cheaper to operate & 158 & 23.7 \\
\hline Low noise level & 144 & 21.6 \\
\hline New trend & 187 & 28.1 \\
\hline Test drive & 186 & 27.9 \\
\hline
\end{tabular}

Note: Respondents were given a list of six factors (Good for the environment; Other people's opinions; Cheaper to operate; Low noise level; New trend; and Test drive) to choose from that would influence their decision to buy an electric vehicle. Respondents chose from one to six factors. For example, 424 or $63.7 \%$ of the respondents chose 'Good for the environment' compared to only 135 or $20.3 \%$ that chose 'Other people's opinions'.
When the responses of females were compared to males, $49 \%$ of females identified "good for the environment" influencing the potential to adopt EVs compared to $58 \%$ of males; $48 \%$ of females identified "new trend" compared to $59 \%$ of males; $44 \%$ of females identified "test drive" compared to $60 \%$ of males; $52 \%$ of females identified "other people's opinions" compared to $58 \%$ of males; $56 \%$ of females identified "cheaper to operate" compared to $54 \%$ of males; and $62 \%$ of females identified "low noise level" factor compared to $45 \%$ of males. A chi-square test shows statistically no significant association based on gender (chi-square $=1.905 ; D F=5 ; p=0.86213$ ). . This indicates that females' and males' potential to adopt EVs are influenced by the same factors.

Respondents were asked to rate the importance of government incentives on the potential to adopt EVs based on a 5-point Likert scale from 1 (strongly disagree) to 5 (strongly agree). $67.4 \%$ agreed that the government should provide incentives for buying an EV. Chi-square test demonstrates a statistically significant association between the desire for government incentives and age group (chi-square $=17.442 ; D F=3$; $p \leq 0.00001$ ). The 19 and below age group was more likely than the 20-24 age group to indicate that the government should provide incentives for buying an EV. Also, a chi-square test shows no statistically significant association between the desire for government incentives and gender (chi-square $=3.801 ; D F=3$; $p=0.1495$ ).

Respondents were asked to rate if EVs can satisfy consumer needs just as effectively as gasoline vehicles on a 5-point Likert scale from 1 (strongly disagree) to 5 (strongly agree). $54 \%$ of respondents agreed that EVs can satisfy consumer needs just as effectively as gasoline vehicles. Chi-square tests demonstrate there was no statistically significant association based on age (chi-square $=2.0976 ; D F=3 ; p=0.1475$ ) and gen$\operatorname{der}$ (chi-square $=7.7106 ; D F=3 ; p=0.0524$ ). Moreover, respondents were asked to rate how likely their next vehicle will be an EV on a 5-point Likert scale from 1 (very likely) to 5 (very unlikely). $49 \%$ of the respondents indicated their next vehicle will likely be an EV. Again, a chi-square test demonstrates there was no statistically significant association based on age (chi-square $=2.0976 ; D F=3 ; p=0.1475$ ) and gender (chi-square $=7.7106 ; D F=3 ; p=0.0524$ ).

Regarding knowledge about EVs, respondents were asked about their sources of knowledge. In Table 2, the results show $67.6 \%$ received knowledge about EVs from internet sources followed by $33.3 \%$ from personal communication. Interestingly, no one in the survey selected the newspaper as a source about their knowledge regarding EVs. Chi-square tests demonstrate there is no statistically significant association based on age (chi-square $=11.34 ; D F=9 ; p=0.25312$ ) and gender (chi-square $=0.651 ; D F=3 ; p=0.88466$ ) .

Respondents were also asked to rate their current knowledge about EVs on a 4-point Likert scale from 
Tab. 2 Sources of knowledge about electric vehicles.

\begin{tabular}{|l|c|c|}
\hline $\begin{array}{l}\text { Sources of knowledge } \\
\text { about electric vehicles }\end{array}$ & Frequency & Percentage \\
\hline Newspapers & 0 & 0.0 \\
\hline Magazines & 91 & 13.7 \\
\hline Television & 196 & 29.4 \\
\hline Internet sources & 450 & 67.6 \\
\hline Personal communication & 222 & 33.3 \\
\hline
\end{tabular}

Note: Respondents were given a list of five sources (Newspapers; Magazines; Television; Internet; Personal communication) from which they get most of their knowledge about electric vehicles. Respondents chose from one to six sources. For example, 61 or $13.7 \%$ of the respondents chose 'Magazines' compared to 450 or $67.6 \%$ that chose 'Internet sources'.

1 (no knowledge) to 4 (good knowledge). 45\% claimed to have little knowledge about EVs and $27 \%$ claimed to have moderate knowledge about EVs. Chisquare tests demonstrate there is no statistically significant association based on age (chi-square =11.34; $D F=9 ; p=0.34212$ ) and gender (chi-square $=0.756$; $D F=3 ; p=0.89322$ ).

Respondents were asked about the importance of advice regarding EVs. 38\% said that advice is important, and they rely on the knowledge of their family and friends, while 29\% said that advise is important and they rely on the knowledge of professionals. Chisquare tests demonstrated there was no statistically significant association based on age (chi-square = 10.33; $D F=7 ; p=0.28741$ ) and gender (chi-square $=$ $0.638 ; D F=3 ; p=0.74388$ ).

\subsection{Factors that undermine the potential to adopt EVs}

There were many factors that were identified that undermine the potential to adopt EVs. The results in Table 3 indicate that most students identified "price" (58\%), followed by "limited driving range" (37\%), and "long recharging time" (36\%) as undermining the potential to adopt EVs. When the data is disaggregated according to age, $67 \%$ of the respondents in the 19 years and below age group identified "price" undermining the potential to adopt EVs compared to $26 \%$ in the $20-24$ age group; $33 \%$ of the respondents in the 19 years and below age group identified "limited driving range" undermining the potential to adopt EVs compared to $43 \%$ in the $20-24$ age group; and $38 \%$ of the respondents in the 19 years and below identified "long recharging time" undermining the potential to adopt EVs compared to 33\% in the 20-24 age group. Chi-square tests show statistically significant association between the 19 and below age group and "price" (chi-square $=62.97 ; D F=3 ; p \leq 0.00001$ ), but no significant association between age and "limited driving range" (chi-square $=0.419 ; D F=3 ; p=0.93629$ ), and "long recharging time" (chi-square $=0.358 ; D F=3$; $p=0.94878$ ). This shows that the 19 years and below group's potential to adopt EVs group is more likely to be undermined by "price" than the 20-24 age group.

Moreover, the "lack of recharging stations" (29\%), "lack of trust in new technologies" (21\%), "lack of consumer choice" (18\%), and "unwillingness to change my lifestyle" (9\%) did not rank as high in importance in terms of undermining the potential to adopt EVs. When the data is disaggregated according to age, $48 \%$ of the respondents in the 19 years and below age group identified "lack of recharging stations" undermining the potential to adopt EVs compared to $43 \%$ in the 20-24 age group; $51 \%$ of the respondents in the 19 years and below age group identified "lack of trust in new technologies" undermining the potential to adopt EVs compared to $42 \%$ in the $20-24$ age group; $45 \%$ of the respondents in the 19 years and below identified "lack of consumer choice" undermining the potential to adopt EVs compared to $52 \%$ in the 20-24 age group; and $41 \%$ of the respondents in the 19 years and below identified "unwillingness to change my lifestyle" undermining the potential to adopt EVs compared to $42 \%$ in the $20-24$ age group. A chi-square test shows statistically no significant association between all age groups and "lack of recharging stations", "lack of trust in new technologies", "lack of consumer choice", and "lack of consumer choice" (chi-square $=5.084 ; D F=9 ; p=0.82693$ ) factors. This demonstrates that all age groups' potential to adopt EVs is undermined by "lack of recharging stations", "lack of trust in new technologies", "lack of consumer choice", and "unwillingness to change my lifestyle" factors.

When the responses of females were compared to males, $62 \%$ of females identified "price" undermining the potential to adopt EVs compared to $65 \%$ of males; $45 \%$ of females identified "limited driving range" compared to $55 \%$ of males; $45 \%$ of females identified "long recharging time" compared to $60 \%$ of males; $55 \%$ of females identified "lack of recharging stations"

Tab. 3 Factors that discourage students from buying an electric vehicle.

\begin{tabular}{|l|c|c|}
\hline $\begin{array}{l}\text { Factors that discourage students } \\
\text { from buying an electric vehicle }\end{array}$ & Frequency & Percentage \\
\hline Price & 386 & 58.0 \\
\hline Long recharging time & 241 & 36.2 \\
\hline Limited driving range & 243 & 36.5 \\
\hline Lack of consumer choice & 118 & 17.7 \\
\hline Lack of recharging stations & 195 & 29.3 \\
\hline Lack of trust in new technologies & 137 & 20.6 \\
\hline Unwillingness to change my lifestyle & 59 & 8.9 \\
\hline
\end{tabular}

Note: Respondents were given a list of seven factors (Price; Long recharging time; Limited driving range; Lack of consumer choice; Lack of recharging stations; Lack of trust in new technologies; Unwillingness to change my lifestyle) to choose from that would discourage them from buying an electric vehicle. Respondents chose from one to seven factors. For example, 386 or $58 \%$ of the respondents chose 'Price' compared to only 241 or $36.2 \%$ that chose 'Long recharging time'. 
compared to $58 \%$ of males; $56 \%$ of females identified "lack of trust in new technologies" compared to $54 \%$ of males; $56 \%$ of females identified "lack of consumer choice" compared to $54 \%$ of males; and $32 \%$ of females identified "unwillingness to change my lifestyle" compared to $38 \%$ of males. A chi-square test shows statistically no significant association based on gender (chi-square $=2.858 ; D F=6 ; p=0.82645$ ). This indicates that females' and males' potential to adopt EVs are undermined by the same factors.

Respondents were asked to rate the advantage of owning an EV over a gasoline vehicle on a 5-point Likert scale from 1 (strongly disagree) to 5 (strongly agree). Most of the respondents (65\%) agreed that owning an EV has an advantage over owning a gasoline vehicle. Chi-square tests show statistically significant association between the advantages of owning an EV over a gasoline vehicle by age group (chi-square $=15.6035 ; D F=3 ; \mathrm{p}=0.0014$ ) as well as gender (chisquare $=12.4608 ; D F=3 ; p=0.006)$. The 19 and below age group were more likely than the 20-24 age group to indicate that owning an EV has an advantage over owning a gasoline vehicle. Also, males were more likely than females to indicate that owning an EV has an advantage over owning a gasoline vehicle.

\section{Conclusions and Implications for Sustainable Transport}

The sample of respondents in this study provides important insights about the perceptions, preferences, and valuation of university students regarding the adoption of EVs as part of a strategy towards sustainable transport. The results show several important findings. The youngest age group's (19 years and below) potential to adopt EVs is more likely to be influenced by environmental factors. This demonstrates a growing awareness about environmental factors among some of the youngest potential adopters of EVs. The same age group is more likely to consider new trends as well as performance influencing the potential to adopt EVs. This indicates that early potential adopters have similar expectations about EVs as they do about gasoline vehicles; they want trendy and well-performing vehicles. Also, the youngest age group is more likely to consider the opinion of others (word of mouth) about EVs, how cheap they are to operate, and noise level. All these factors play an important role in terms of the potential to adopt EVs.

There were also many factors that were identified that undermined the potential to adopt EVs. Among the most important factors was cost, especially for the youngest age group (19 and below). This indicates that early potential adopters may not be financially stable and may not adopt EVs because of their higher cost. Also, all the age groups that were surveyed in this study pointed to other issues that are potential barriers to adopting EVs. For example, the lack of charging infrastructure, the novelty of the technology, and the unwillingness for potential adopters to make a lifestyle change. Furthermore, the findings suggest that although environmental benefits of EVs have a major influence on EV adoption they are ranked after cost and performance.

In terms of a comparison between the overall advantages of owning an EV over a gasoline vehicle, the 19 and below age group males indicated that owning an EV has an advantage over owning a gasoline vehicle. Also, nearly half of the respondents indicated their next vehicle will likely be an EV. This shows that overall, a moderate to high interest in EVs exists despite several reservations expressed towards EVs. In general, attitudes towards EVs were neither wholly positive nor wholly negative, however, completely negative attitudes to EV technology should not be ignored.

Evidence from this study emphasizes the need to address socio-technical barriers facing EVs. As previously mentioned, some major challenges faced by EVs include the lack of charging infrastructure, the novelty of the technology, and so on; however, consumer acceptance is important as it is key to the commercial success or failure of EVs, even if the other criteria are met. A major potential barrier to widespread $\mathrm{EV}$ adoption detected among our target group is the uncertainty associated with the EV technology and recharging sources. Some of this uncertainty may be attributed to unfamiliarity with EV technology, but may also be attributed to the older age groups (20 and older) females not being convinced that EVs are a better option than gasoline vehicles.

All age groups, especially the 19 and below age group, favoured economic incentives. This, however, may have little effect on EV market penetration if consumers have low confidence in EV technology. Therefore, certain measures need to be taken to increase the market share of EVs. This includes education, increased investments in EV technology, infrastructure, battery swap programs, extensive warranties on the EV batteries, and increased government credits to subsidize the cost of EVs. Moreover, the study demonstrates the importance of acquiring knowledge about EVs from sources on the internet, word of mouth, and family and friends. Since public opinion can be influenced through media and social networks, policy makers can use this medium to influence the public appreciation for financial and non-financial benefits of adopting EVs such as energy security and reduction of ecological footprint.

The current research contributes to the existing academic literature in several ways. Issues such as environmental concerns, trendiness, operation costs, drivability, other people's opinions and government incentives are among the most important factors that affect potential adopter attitudes with no significant difference between male and female responses. This is in line with other studies that examine the 
importance of a variety of incentives that promote the adoption of EVs, 'real world' driver experience, and the symbolic value that vehicles have regarding potential adopter attitudes (see, for example, Heffner et al. 2006; Jensen et al. 2013; Zhang et al. 2018). Among the factors that detract potential adopter attitudes are purchase price, limited driving range, long recharging time, lack of recharging stations, lack of trust in new technologies, lack of consumer choice, and the unwillingness to change one's lifestyle. Other studies in this vein that highlight the uncertainties surrounding EVs point to issues such as ignorance or misunderstanding regarding novel technologies, lack of infrastructure for recharging, the recharging time, and the limited driving range (see, for example, Axsen et al. 2017; Carley et al. 2019; Figenbaum and Kolbenstvedt 2016). Such findings are similar to other research (see, for example, Adnan et al. 2017; Liao et al. 2017; Rezvani et al. 2015) that provides comprehensive reviews of extensive number of studies. This confirms that social, financial, technical, and infrastructure attributes continue to drive decision-making processes.

The study's novel contribution to the academic literature relates to the way age plays an important factor in determining the potential to adopt EVs. The study disaggregates the ages of university students into four categories: (1) 19 years and below; (2) 20-24 years; (3) 25-29 years; and (4) 30 years and over. Since most of the respondents (55\%) were 19 years and below, they are lower than the age requirement for obtaining a license in the UAE and most likely do not own a vehicle. Accordingly, most of the respondents fell into the category of 'potential adopters of EVs' (i.e., potential consumers).

Moreover, the chi-square tests show a statistically significant association between the 19 years and below age group and "good for the environment" (chisquare $=355.04 ; D F=3 ; p \leq 0.00001$ ), "new trend" (chi-square $=185.09 ; D F=3 ; p \leq 0.00001$ ), "test drive" (chi-square $=148.52 ; D F=3 ; p \leq 0.00001$ ), "other people's opinions" (chi-square = 118.24; $D F=3 ; p \leq 0.00001$ ), "cheaper to operate" (chi-square = 107.94; $D F=3 ; p \leq 0.00001$ ), "low noise level" (chisquare $=136.61 ; D F=3 ; p \leq 0.00001)$, "the desire for government incentives" (chi-square = 17.442; $D F=3 ; p \leq 0.00001$ ), "price" (chi-square = 62.97; $D F=3 ; p \leq 0.00001$ ), and "EV has an advantage over owning a gasoline vehicle" (chi-square = 15.6035; $D F=3 ; p=0.0014$ ). This demonstrates that these factors are more likely to influence the 19 years and below group's potential to adopt EVs than any other age group in the study.

Given these findings, a good case can be made to more carefully take into consideration the importance of age, especially younger people, when examining issues related to the adoption of EVs. There are several reasons for this. In the UAE, there has been greater emphasis placed on issues related to environmental sustainability through several government initiatives based on the sustainable development goals set out by the United Nations for 2030 (see The United Arab Emirates' Government Portal 2020). While unlike many Western countries, where such issues have been at the forefront for many years, in the UAE they are relatively new. The initiatives from different government entities, however, have trickled down into the education system. For example, the UAE curriculums at the primary and secondary levels have been revised to include a more comprehensive examination of issues related to environmental sustainability. Students entering the university system in the UAE today are much more aware of the pressing issues regarding the environment, including the problem of $\mathrm{CO}_{2}$ emissions from gasoline engines, than previous cohorts. Greater awareness of such issues has a determining effect on young people's (19 years and below) potential to adopt EVs.

The UAE, however, is not alone in this regard. Internationally, young people together with the United Nations Framework Convention on Climate Change (UNFCCC) have been involved in the intergovernmental climate change negotiations. Such initiatives have produced greater awareness of issues related to climate change, such as $\mathrm{CO}_{2}$ emissions from gasoline vehicles, through the publication of educational resources, UNFCCC conferences, good practices, and partnerships (see United Nations Climate Change 2020). In addition, there has been a variety of protests by young people in what has been referred to as the 'climate change protests'. Thousands of students from the US, UK, Australia, and other countries expressed their dismay with the lack of action by governments and corporations regarding climate change (see, for example, BBC 2020; Brook n/d; The Guardian n/d). The point here is that a qualitative change is occurring mostly in the mindset of younger generations regarding climate change. Young people are increasingly more willing to adopt policies and practices that are environmentally sustainable. Based on these factors, governments seeking more environmentally sustainable policies and industry seeking to increase the sale of EVs would benefit from directing their sustainable transport strategies toward potential adopters of EVs rather than simply attempting to convince already existing consumers. This would be an effective strategy as young potential adopters of EVs are seeking alternative products and practices that are more environmentally sustainable.

\section{References}

Adnan, N., Nordin, S. M., Rahman, I. (2017). Adoption of PHEV/EV in Malaysia: a critical review on predicting consumer behaviour. Renewable and Sustainable Energy Reviews 72, 849-862, https://doi.org/10.1016/j.rser .2017.01.121. 
Axsen, J., Dusyk, N., Cairns, J., Goldberg, S. (2018): Consumer Lifestyle and Response to Low-Carbon Technologies: Semistructured Interviews with Plug-In Electric Vehicle Owners (No. 18-01065).

Axsen, J., Langman, B., Goldberg, S. (2017): Confusion of innovations: mainstream consumer perceptions and misperceptions of electric-drive vehicles and charging programs in Canada. Energy Research and Social Science 27, 163-173, https://doi.org/10.1016/j.erss .2017.03.008.

BBC (2020): Climate change: Extinction Rebellion end blockade at Shell's Aberdeen HQ. Retrieved from https:// www.bbc.com/news/uk-scotland-north-east-orkney -shetland-51132110?intlink_from_url=https://www.bbc .com/news/topics/cjyykdwmw58t/uk-climate-change -protestsandlink_location=live-reporting-story.

Bhattacharya, S., Constantinides, G. M. (2005): Theory of valuation. World Scientific, https://doi.org/10.1142 /5860.

Brook, B. (n/d). 'My teacher doesn't know I'm here': Tens of thousands of teens gather for climate change protests. Retrieved from https://www.news.com.au /technology/environment/climate-change/my-teacher -doesnt-know-im-here-tens-of-thousands-of-teens -gather-for-climate-change-protests/news-story /77234a1c1f3138d94a860c09e4c70b03.

Bühler, F., Cocron, P., Neumann, I., Franke, T., Krems, J. F. (2014): Is EV experience related to EV acceptance? Results from a German field study. Transportation Research Part F: Traffic Psychology and Behaviour 25, 34-49, https://doi.org/10.1016/j.trf.2014.05.002.

Carley, S., Siddiki, S., Nicholson-Crotty, S. (2019): Evolution of plug-in electric vehicle demand: Assessing consumer perceptions and intent to purchase over time. Transportation Research Part D: Transport and Environment 70, 94-111, https://doi.org/10.1016/j.trd 2019.04.002.

Coffman, M., Bernstein, P., Wee, S. (2017): Electric vehicles revisited: A review of factors that affect adoption. Transport Reviews 37(1), 79-93, https://doi.org/10 $.1080 / 01441647.2016 .1217282$.

DOTAD (2009): Surface transport master plan. Department of Transport.

Figenbaum, E., Kolbenstvedt, M. (2016): Learning from Norwegian Battery Electric and Plug-in Hybrid Vehicle users: Results from a survey of vehicle owners. TØI report, (1492/2016).

Franke, T., Krems, J. F. (2013): What drives range preferences in electric vehicle users? Transport Policy 30, 56-62, https://doi.org/10.1016/j.tranpol.2013 .07 .005 .

Franke, T., Günther, M., Trantow, M., Krems, J. F. (2017): Does this range suit me? Range satisfaction of battery electric vehicle users. Applied Ergonomics 65, 191-199, https://doi.org/10.1016/j.apergo.2017.06.013.

Goldstein, E. B. (2009): Sensation and perception. Cengage Learning.

Graham-Rowe, E., Gardner, B., Abraham, C., Skippon, S., Dittmar, H., Hutchins, R., Stannard, J. (2012): Mainstream consumers driving plug-in battery-electric and plug-in hybrid electric cars: a qualitative analysis of responses and evaluations. Transportation Research Part A 46, 140-153, https://doi.org/10.1016/j.tra.2011.09 .008 .
Hardman, S. (2019): Understanding the impact of reoccurring and non-financial incentives on plug-in electric vehicle adoption - a review. Transportation Research Part A: Policy and Practice 119, 1-14, https:// doi.org/10.1016/j.tra.2018.11.002.

Haustein, S., Jensen, A. F. (2018): Factors of electric vehicle adoption: A comparison of conventional and electric car users based on an extended theory of planned behavior. International Journal of Sustainable Transportation 12(7), 484-496, https://doi.org/10.1080/15568318 .2017.1398790.

Heffner, R., T. Turrentine, Kurani, K. (2006): A Primer on Automobile Semiotics. University of California, Davis: Institute of Transportation Studies.

International Energy Agency (2018): Key world energy statistics. Paris: International Energy Agency.

International Renewable Energy Agency (2018): Global energy transformation: A roadmap to 2050. Abu Dhabi: International Renewable Energy Agency.

Jensen, A. F., Cherchi, E., Mabit, S. L. (2013): On the stability of preferences and attitudes before and after experiencing an electric vehicle. Transportation Research Part D: Transport and Environment 25, 24-32, https://doi.org/10.1016/j.trd.2013.07.006.

Krause, R. M., Lane, B. W., Carley, S., Graham, J. D. (2016): Assessing demand by urban consumers for plug-in electric vehicles under future cost and technological scenarios. International Journal of Sustainable Transportation 10(8), 742-751, https://doi.org/10 $.1080 / 15568318.2016 .1148213$.

Lane, B. (2011): Market Delivery of Ultra-Low Carbon Vehicles in the UK. RAC Foundation, London.

Liao, F., Molin, E., Timmermans, H., van Wee, B. (2019): Consumer preferences for business models in electric vehicle adoption. Transport Policy 73, 12-24, https:// doi.org/10.1016/j.tranpol.2018.10.006.

Liao, F., Molin, E., van Wee, B. (2017): Consumer preferences for electric vehicles: a literature review. Transport Reviews 37(3), 252-275, https://doi.org/10.1080 /01441647.2016.1230794.

Mueller, K., Sgouridis, S. (2011): Simulation-based analysis of personal rapid transit systems: Service and energy performance assessment of the Masdar City PRT case. Journal of Advanced Transportation 45, 252-270, https://doi.org/10.1002/atr.158.

Noppers, E. H., Keizer, K., Bockarjova, M., Steg, L. (2015): The adoption of sustainable innovations: The role of instrumental, environmental, and symbolic attributes for earlier and later adopters. Journal of Environmental Psychology 44, 74-84, https://doi.org/10.1016/j.jenvp 2015.09.002.

Qian, L., Grisolía, J. M., Soopramanien, D. (2019): The impact of service and government-policy attributes on consumer preferences for electric vehicles in China. Transportation Research Part A: Policy and Practice 122, 70-84, https://doi.org/10.1016/j.tra.2019.02.008.

Rezvani, Z., Jansson, J., Bodin, J. (2015): Advances in consumer electric vehicle adoption research: A review and research agenda. Transportation Research Part D: Transport and Environment 34, 122-136, https://doi .org/10.1016/j.trd.2014.10.010.

Schneidereit, T., Franke, T., Guenther, M., Krems, J. F. (2015): Does range matter? Exploring perceptions of electric vehicles with and without a range extender among 
potential early adopters in Germany. Energy Research and Social Science 8, 198-206, https://doi.org/10.1016 /j.erss.2015.06.001.

Schuitema, G., Anable, J., Skippon, S., Kinnear, N. (2013): The role of instrumental, hedonic and symbolic attributes in the intention to adopt electric vehicles. Transportation Research Part A: Policy and Practice 48, 39-49, https:// doi.org/10.1016/j.tra.2012.10.004.

Sgouridis, S., Abdullah, A., Griffiths, S., Saygin, D., Wagner, N., Gielen, D., Reinisch, H., McQueen, D. (2016): RE-mapping the UAE's energy transition: An economywide assessment of renewable energy options and their policy implications. Renewable and Sustainable Energy Reviews 55, 1166-1180, https://doi.org/10.1016/j.rser 2015.05.039.

Sgouridis, S., Helmers, E., Al Hadhrami, M. (2018): Lightduty electric vehicles in the gulf? Techno-economic assessment and policy implications. International Journal of Sustainable Transportation 12(2), 92-106, https://doi.org/10.1080/15568318.2017.1332256.

She, Z. Y., Sun, Q., Ma, J. J., Xie, B. C. (2017): What are the barriers to widespread adoption of battery electric vehicles? A survey of public perception in Tianjin, China. Transport Policy 56, 29-40, https://doi.org/10.1016 /j.tranpol.2017.03.001.

Skippon, S. M., Kinnear, N., Lloyd, L., Stannard, J. (2016): How experience of use influences mass-market drivers' willingness to consider a battery electric vehicle: a randomised controlled trial. Transportation Research Part A: Policy and Practice 92, 26-42, https://doi.org /10.1016/j.tra.2016.06.034.
Slovic, P. (1995): The construction of preference. American Psychologist 50(5), 364-371, https://doi.org /10.1037/0003-066X.50.5.364.

The United Arab Emirates' Government Portal (2020). Efforts towards Sustainability. Retrieved from https:// government.ae/en/information-and-services /environment-and-energy/environmental-protection /efforts-towards-sustainability.

United Nations (2011): 2012 the International Year of Sustainable Energy for All. Retrieved from http://www .un.org/en/events/sustainableenergyforall/index .shtml.

United Nations Climate Change (2020): Youth for Climate Action. Retrieved from https://unfccc.int/topics /education-and-outreach/workstreams/youth -engagement.

WBGU (2012). World in transition. German Advisory Council on Global Change.

White, L. V., Sintov, N. D. (2017): You are what you drive: Environmentalist and social innovator symbolism drives electric vehicle adoption intentions. Transportation Research Part A: Policy and Practice 99, 94-113, https://doi.org/10.1016/j.tra.2017.03.008.

World Health Organization (2018): Global status report on road safety 2018: Summary (No. WHO/NMH /NVI/18.20). World Health Organization.

Zhang, X., Bai, X., Shang, J. (2018): Is subsidized electric vehicles adoption sustainable: Consumers' perceptions and motivation toward incentive policies, environmental benefits, and risks. Journal of Cleaner Production 192, 71-79, https://doi.org/10.1016/j.jclepro.2018.04.252. 